\title{
Control of Wall Pressure Flow Field with Micro Jets and Control Effectiveness
}

\author{
Musavir Bahir ${ }^{1}$, Qummare Azam ${ }^{2}$, S. A. Khan ${ }^{3}$, M. Ahmed Ali Baig ${ }^{4}$ \\ ${ }^{1}$ Research Scholar, School of Aerospace Engineering, University Sains Malaysia (USM), Penang, Malaysia \\ ${ }^{2}$ School of Mechanical Engineering, University Sains Malaysia (USM), Penang, Malaysia \\ ${ }^{3}$ Professor, Department of Mechanical Engineering, International Islamic University Malaysia (IIUM), \\ Malaysia \\ ${ }^{4}$ Professor, Department of Mechanical Engineering, CMR Technical Campus, Hyderabad, India
}

\begin{abstract}
This paper presents an experimental study of airflow from convergent-divergentnozzles discharged into enlarged duct, focusing attention on the flow development in the duct. To investigate the influence of active control on the flow field developed in the duct, the tiny jets of 0.05 mmradiuslocated at $90^{\circ}$ interval along the base at $6.5 \mathrm{~mm}$ from the main jet were employed. The Mach number tested in the present study was 1.48. The area ratio tested was 2.56. The NPR tested are from 3, 5, 7, and 9 respectively. The L/D ratio of the duct was varied from 10 to 1 . The level of expansion at the nozzle exit influences the wall pressure very strongly. When the micro jets were activated they found to influence the base region, taking the wall pressure to considerably higher values, for most of the cases. Flow field in the duct with and without control remains the same.
\end{abstract}

\section{Introduction}

With the demand to acquire the advanced launchers, rockets and scramjets to meet the future economic requirements, the design aspects have to be researched further. In the development of advanced future nozzle designs for propulsion systems, the performance increases along with the reduction of cost, which is of course the most encouraging issue. Therefore, in base flow aerodynamics, a lot of concentration is being given to the base flow of the aerodynamic vehicles. The scope ranges from the nozzle design, flow field interactions, shock wave-boundary layer interactions, base drag and advanced concepts for these investigations. For example, in Europe, high area ratio concept is gaining strength for future engines, therefore is investigated to par with the requirements[1]. The performance is highly dependent on the aerodynamic design of the expansion nozzle, the main parameters being the area ratio and length to diameter ratio[2]. The literature supports the dependence of the parameters to control the base drag of the flow. As the separation phenomenon is dominant at higher Mach numbers, different kinds of dynamic loads and phenomenon occur when the flow is separation. One such phenomenon is wall pressure effect on the flow analysis, which in turn affects the performance of the flow.There are two types of control techniques employed to control the flow viz. active and passive categories[3, 4]. Passive methods do not require external energy input but involve fixed geometrical modifications and hence are advantageous from an integration and robustness standpoint [5]. However, passive techniques generally do not work well at off-design conditions and may introduce other penalties, such as increased drag. In active flow control schemes, an external energy input is used to introduce certain disturbances, ideally at critical points, in the flow field and tailor the natural behavior of the flow according to the control objectives. Active control allows more flexibility than passive control[5]. However, for the active control strategy to be deemed practical, the energy expenditure needed for control should have some acceptable relation to the benefits achieved through control. In other words, the control should be efficient in addition to being effective. Therefore, the unstable nature of this flow can be controlled using both active and passive methods. The result from the previous research has proved that active control is not only a workable technology for minimizing the unstable behavior, but also the approach is easily imitated for large scale applications [6-8]. It was investigated that the pressure in the augmented area is related to the boundary layer type and thickness upward of the expansion [9].The effectiveness of bleed in the wake region and the flow field at higher Mach number showed that the pressure remains uniform across the plane $[10,11]$. Initially, the average base pressure showed a gradual increment with the bleed flow rate, and the optimal results were characterized by a weak corner expansion, minimum shear value and absence of recirculation phenomenon. The experimental investigation to study the effectiveness of tiny jets at various level of expansion to control the base pressure in the abruptly expanded ducts is carried out [12-15].From their investigation they observed that the base enhancement is more than $100 \%$ for some set of parameters and control does not alter 
The experiments were conducted to study the effects of splitter platefor various conditions(i. e. $\mathrm{h} / \mathrm{l}=\langle>$ 1) by Rathakrishnan[16]. The result was very effective in terms of percentage, as splitter plate reduced the base drag without affecting the wall pressure distribution. It is also found that many techniques can be used to reduce or even suppress the flow separation. These techniques include puffing or imbibition of air flow through channels[17, 18] or holes[19], sequential arrangement of pulsed jets, actuators[20]and others. All of these techniques come with pros and cons, as the steady puffing or suction through orifices normal to free stream flow and located close down stream of the separation line has been revealed to be effective in reattaching the flow, but such devices need a continuous supply of mass flow which is difficult to attain.

The experiments were conducted to study the effects of tiny jets for various conditions (i.e. $\mathrm{Pe} / \mathrm{Pa}=\langle>$ 1) by Rathakrishnan and others [7, 12, 15, 21-25]. The result was very effective in terms of percentage, as micro jets reduced the base drag without affecting the wall pressure distribution. It is found that many techniques can be used to reduce or even suppress the flow separation. The experiments were conducted to study the effects of tiny jets for various conditions (i.e. $\mathrm{Pe} / \mathrm{Pa}=\langle>1$ ) by Khan and others [15, 24-30]. The result was very effective in terms of percentage, as micro jets reduced the base drag without affecting the wall pressure distribution. It is found that many techniques can be used to reduce or even suppress the flow separation.

Therefore in this study, we have employed micro jets as active control devices in our examination, the correlation of base pressure change with flow Mach number has been demonstrated at different L/D ratios.

\section{Experimental Procedure}

The fringed nozzle-enlarged duct is fixed at the end of the settling chamber by a slot holder arrangement. The base pressure taps and wall pressure taps are measured matching the channels of pressure sensors connected on bread board to a data logger at a time in each run for different Mach numbers and expansion levels. Pressure sensors used for this experiment are Honeywell TruStability® Board Mount Pressure Sensors, HSC Series - High Accuracy, Low Pressure Sensors - HSCDANN015PAAA5 (Absolute) and HSCDANN010BGAA5 (Gauge). Data acquisition is done with the help of Graphtec MIDI LOGGER GL820, with a 20- channel input. The model area ratio $(\mathrm{D} 2 / \mathrm{d} 2)$ is varied in the range from 1.5 to 4 . The L/D ratio is another variable parameter 4, 5, 6 for pipe diameters $19 \mathrm{~mm}, 16 \mathrm{~mm}$, and $13 \mathrm{~mm}$ respectively. NPR can be calculated accurately, while Mach number can be estimated from isentropic relationships. The measurements include the stagnation pressure of the settling chamber, the base pressure, and the wall pressure distribution along the length of the duct. All of the pressures are measured using absolute pressure sensors, except for the settling chamber pressure, which is measured using gauge pressure sensor. A data logger is used for data acquisition. Tests done using pressure sensors and data logger for a particular case with repeated testing for the same, showed that it was repeatable within $\pm 2 \sim 3 \%$ accuracy with the previous results of the same case.

\section{Results and Discussion}

One of the major difficulty encountered while working in the area of sudden expansion is that the flow field in the duct becomes oscillatory because of the "Ejector Pump" action at the base region i.e. the vortices are getting formed at the base because of expansion of the shear layer from the nozzle and getting ejected to the main flow continuously. In the literature this action was known as the "Jet Pump action". This action renders the flow in the duct to become oscillatory. Therefore, it is mandatory on the part of a researcher working in this area to monitor the flow development in the duct. In other words when we employ a control to modify the base pressure level, there is a possibility that the control might augment the flow field in the duct. To take care for this undesirable effect the wall pressure distribution in the duct was measured for all combination of parameters of the present investigation. Results for L/D for L/D = 10 for NPRs 9, 7,5, and 11 are presented in figures 1((a) to (d)). From Fig. 1(a) it is seen that at NPR $=9$ the entire flow field in the duct is full of waves, the very first shock wave is so powerful that the wall pressure is equal to the atmospheric pressure and then through the next shock the wall pressure assumes higher value than the atmospheric pressure after the reflection from the wall, however, at this point the control results in reduction of wall pressure by $40 \%$ and the same phenomena continues with in $\mathrm{x} / \mathrm{L}=0.4$ through the next two shock and expansion waves. Later, again it under goes through compression and expansion waves. In Fig. 1 (b), results for NPR $=7$ are shown, the flow field is similar except in the strength of the shock waves has come down due to the decreased value of the NPR 


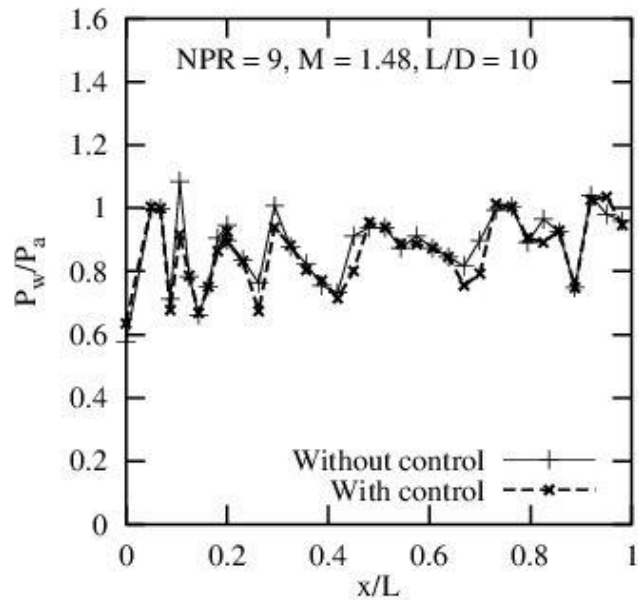

Fig. 1 (a)

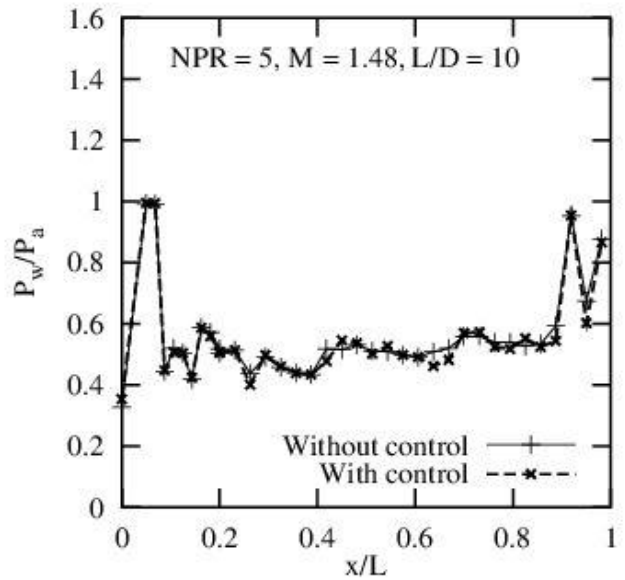

Fig. 1 (c)

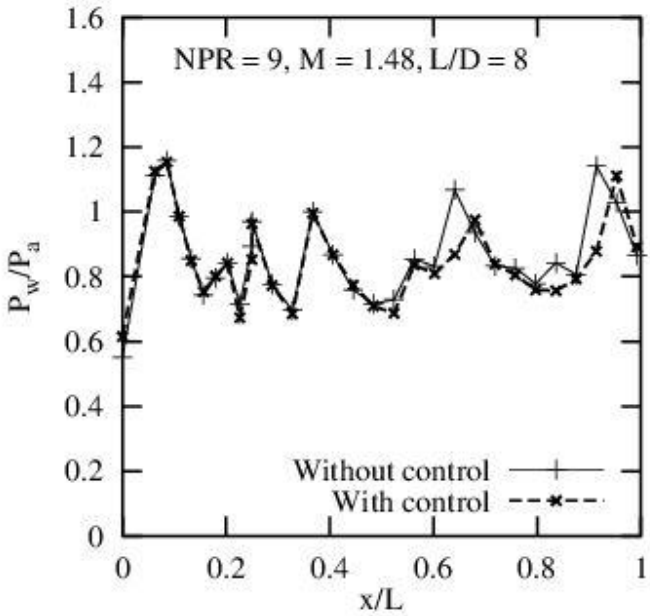

Fig. 2 (a)

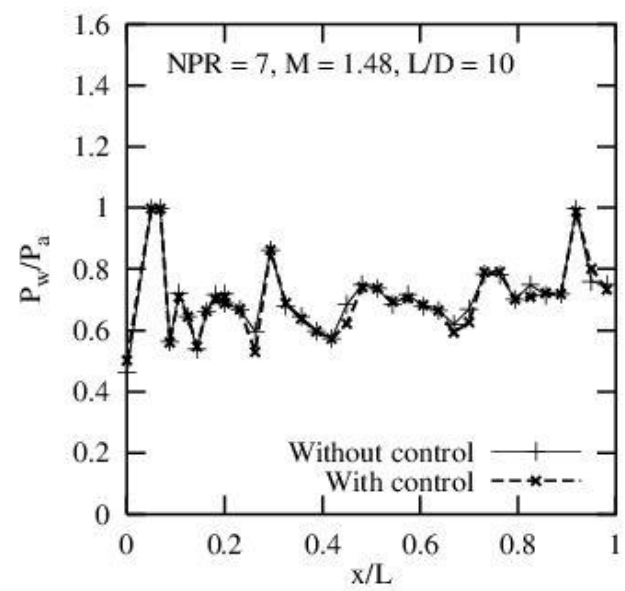

Fig. 1(b)

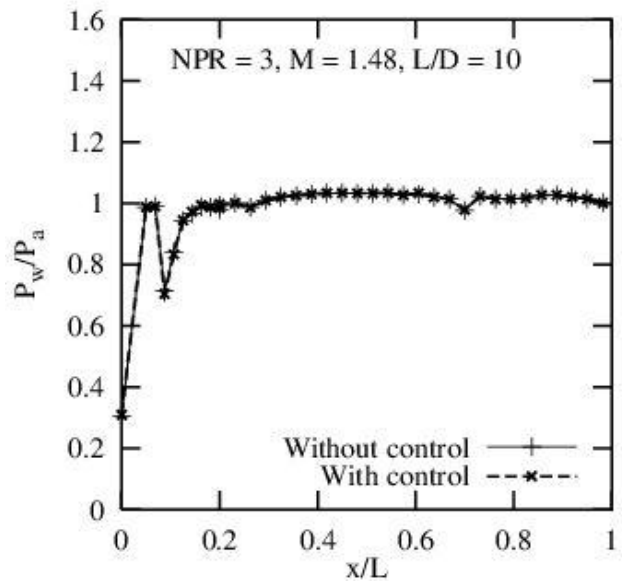

Fig. 1(d)

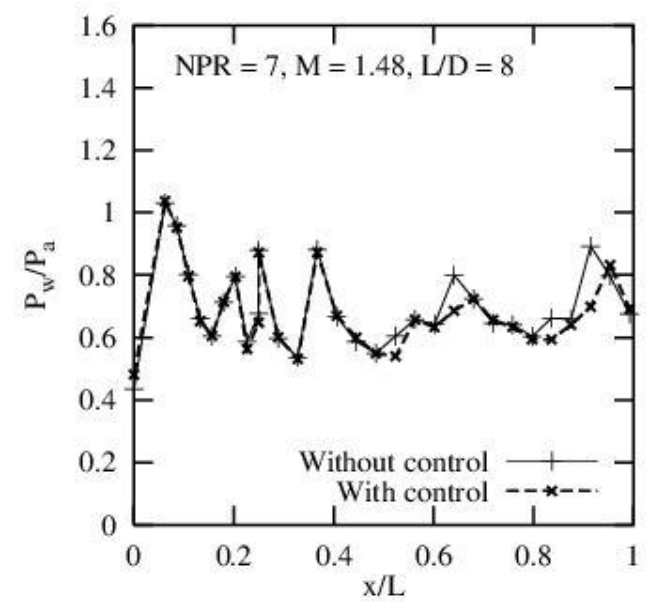

Fig. 2(b)

Fig. 1((c) to (d)) shows the wall pressure distribution for NPR 5 and 3, here jets are under and over expanded at NPR $=5$ and 3, as it was seen in previous case that the first shock is very strong it continue to be the same. Since the flow has to undergo further expansion therefore, in Fig. 1(c) we see that the flow field is associated with the compression and expansion waves. However, for NPR $=3$, it contains only two oblique shocks and after that all pressure value has reached almost to the level of atmospheric pressure.

Results for $\mathrm{L} / \mathrm{D}=8$ are shown in Fig. $2((\mathrm{a} 0$ to $(\mathrm{d}))$, as discussed above the wall pressure flow field is associated with the compression and expansion waves for NPRs 9, 7, and 5 and for NPR 3 no such trend is seen. Further, due to decreased L/D, the initial jump in the wall pressure has gone up by $20 \%$ and $10 \%$ for NPRs 9 and 7. 


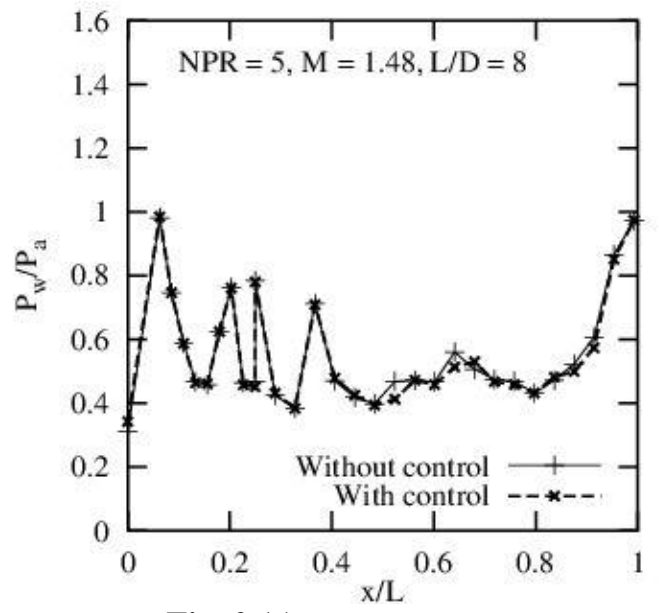

Fig. 2 (c)

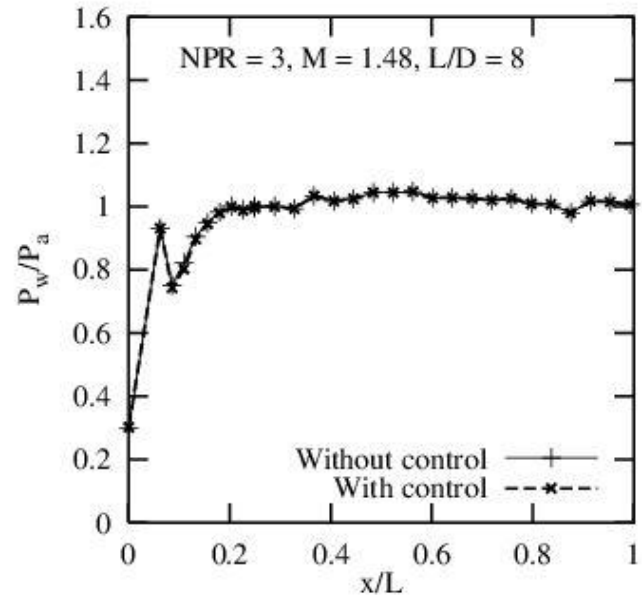

Fig. 2(d)

Results for L/D = 6 are presented in Figs. 3((a) to (d)), for the same NPRs, for NPRs 9 and 7 there is a sudden jump in the initial wall pressure and it has gone up by $60 \%$ and $35 \%$ respectively for NPRs 9 and 7 , however, for NPRs 5 and 3 the trend is the same as discussed earlier. Another phenomenon observed is that number waves have reduced considerable due to the short duct length.

Results for NPRs 9, 7, 5 and 3 for L/D $=5$ are shown in Figures 4((a) to (d)), they similar results as discussed earlier for NPRs 9 and 7 for this L/D $=5$ as well, but when we see the results for NPRs 5 and 3 there is marginal change in the terms of shock strength and number of waves due to the reduction in the duct length. Results for $\mathrm{L} / \mathrm{D}=4$ and are on the similar lines as that of $\mathrm{L} / \mathrm{D}=5$ as shown in Figs. 5((a) to (d)) and Figs 6((A) to (d)), and for these L/Ds the lowest wall pressure values for all the NPRs remains the same. Never the less in the of $\mathrm{L} / \mathrm{D}=3$, due to the influence of the back pressure the number of compression and expansion waves have reduced drastically, but for NPRs 7 and 5 it has aggravated. However, for L/D = 3, with a number of oblique shock waves the flow recovery takes place.

Results for L/D = 2 are shown in Figs. 7((a) to (d)), trend of the flow field remains the as that of $L / D=$ 3 for NPRs 9, 7 and 5, but at NPR = 3, without control the suction which was created for all the L/Ds NPRs was created is no more visible when active controls are employed and the value of wall pressure increases from as low as 0.3 to 0.75 , this behavior is due to the combined effect of NPR, L/D, and due to the influence of ambient atmospheric pressure.

Results for the lowest L/D = 1 are presented in Figs. 8((a) to (d)), the flow is no more attached at NPR $=3$ as seen in Fig. 8(d). Another observation is that when were employed there is marginal increase in wall pressure for all the NPRs in the range 9 to 7 for $\mathrm{L} / \mathrm{D}=1$. In view of the extremely short duct length we should consider the results for $\mathrm{L} / \mathrm{D}=10$ to 2 for analysis.

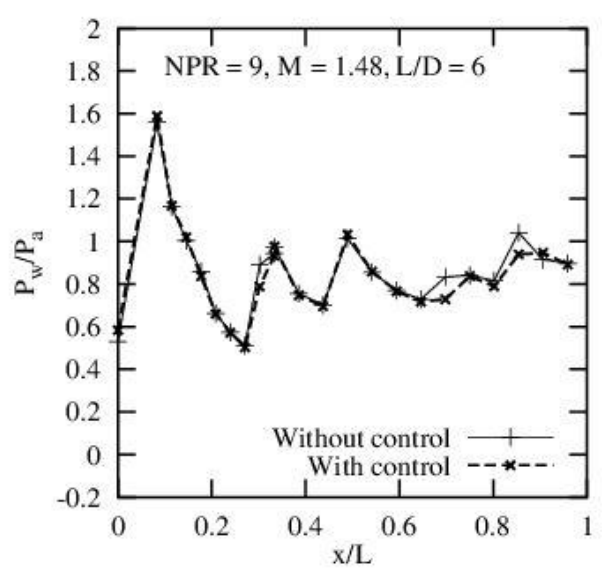

Fig. 3 (a)

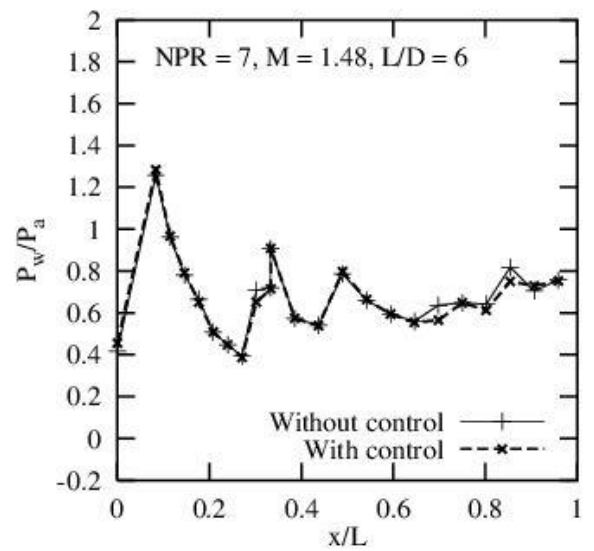

Fig. 3(b) 


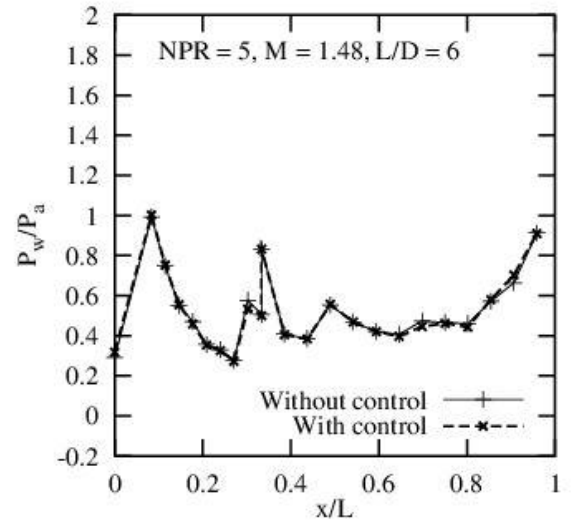

Fig. 3 (c)

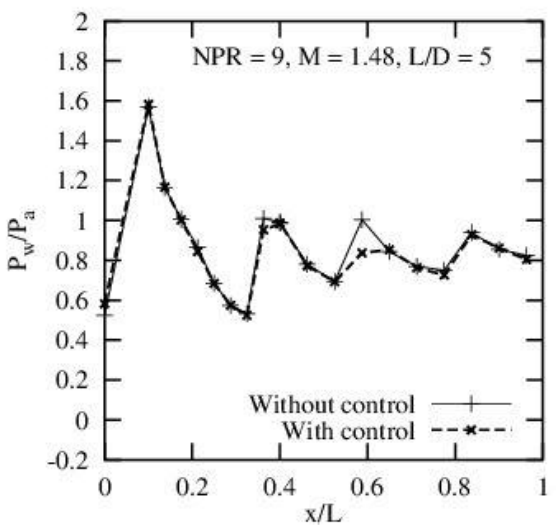

Fig. 4 (a)

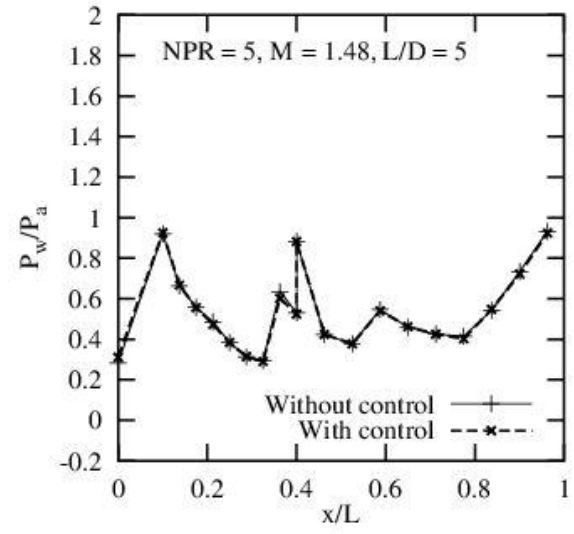

Fig. 4 (c)

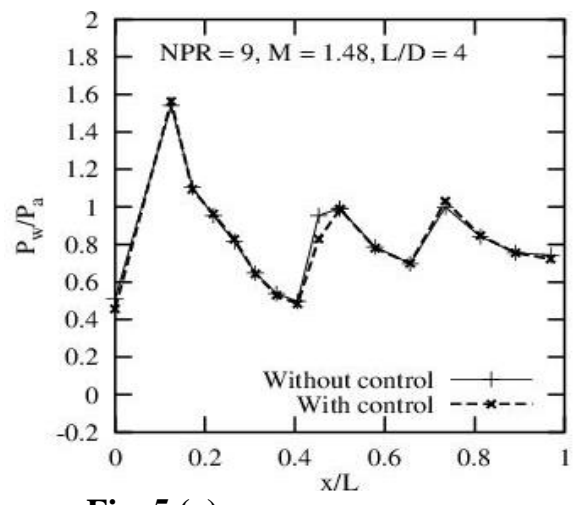

Fig. 5 (a)

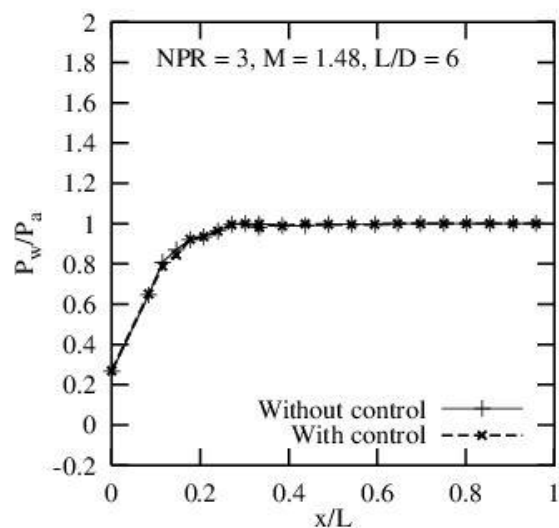

Fig. 3(d)

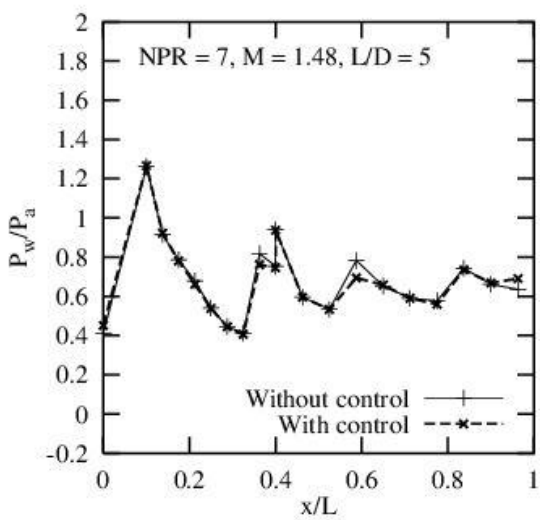

Fig. 4(b)

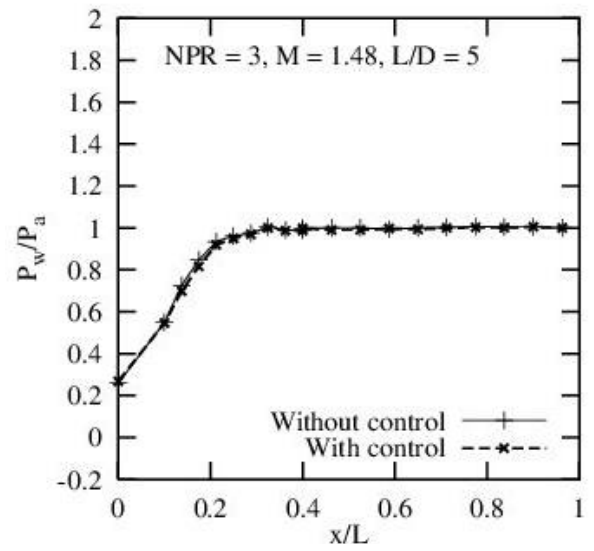

Fig. 4(d)

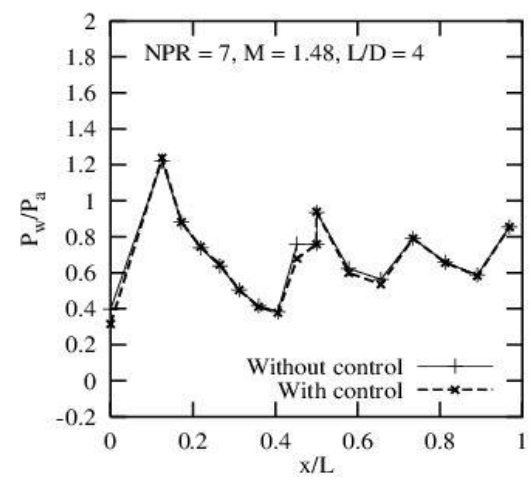

Fig. 5(b) 


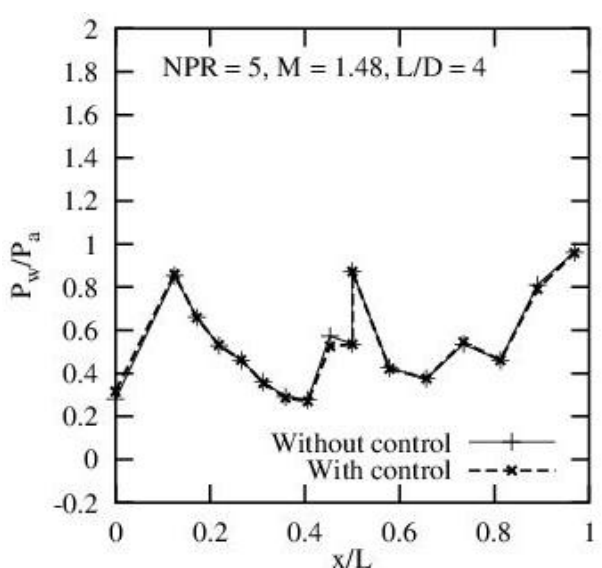

Fig. 5 (c)

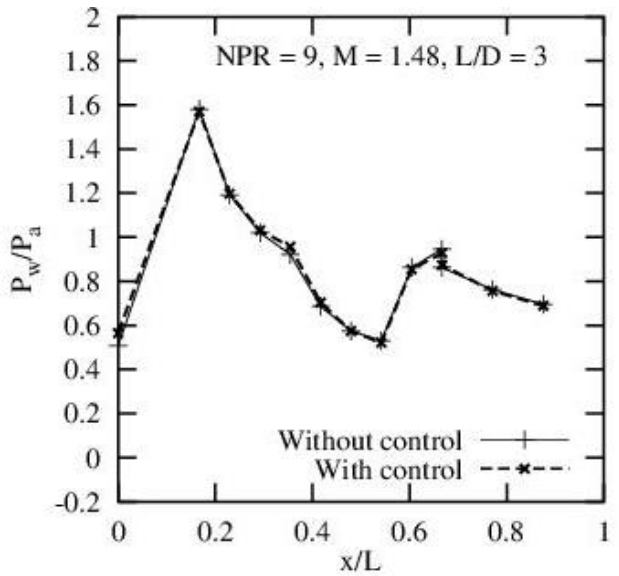

Fig. 6 (a)

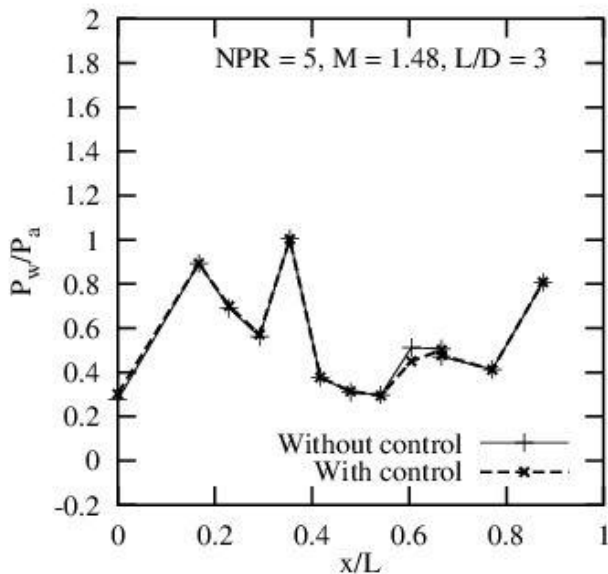

Fig. 6 (c)

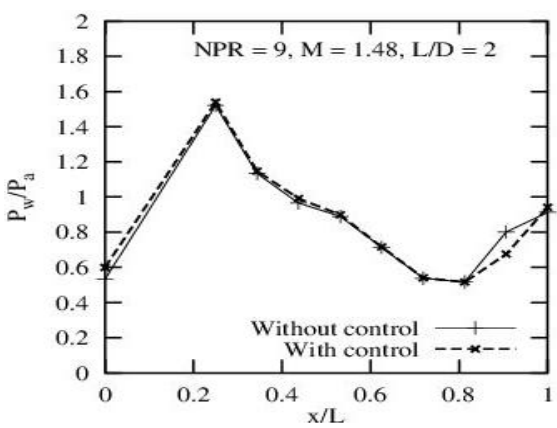

Fig. 7 (a)

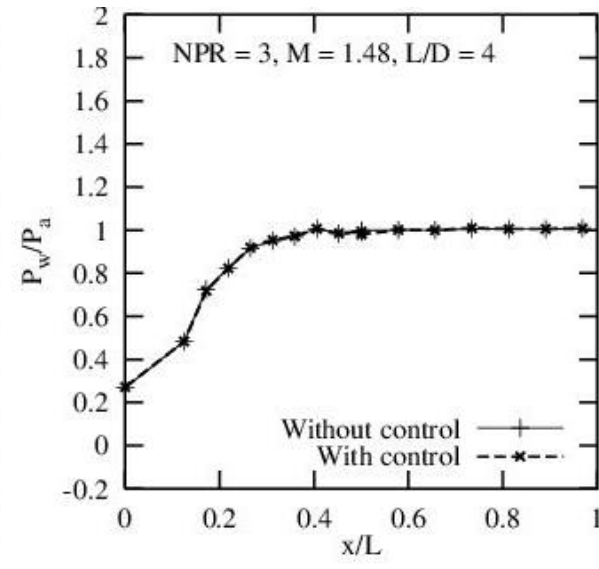

Fig. 5(d)

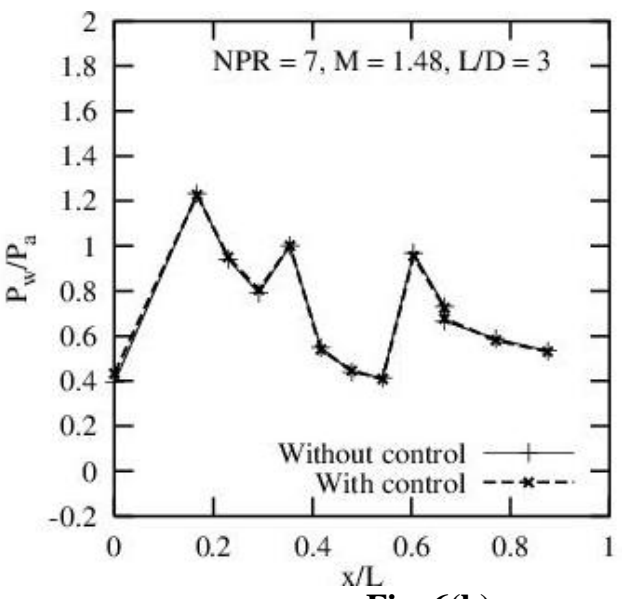

Fig. 6(b)

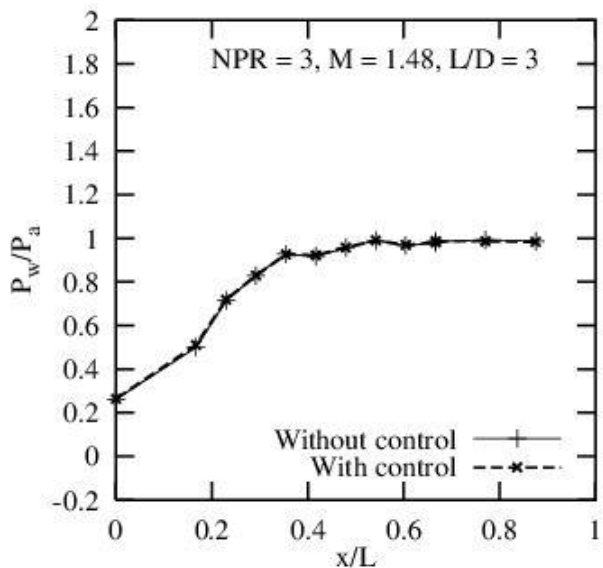

Fig. 6(d)

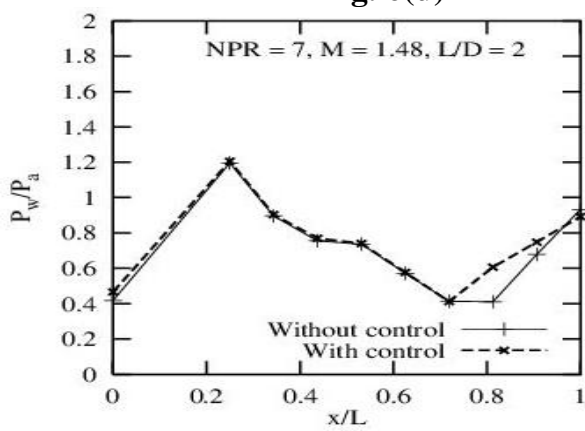

Fig. 7(b) 


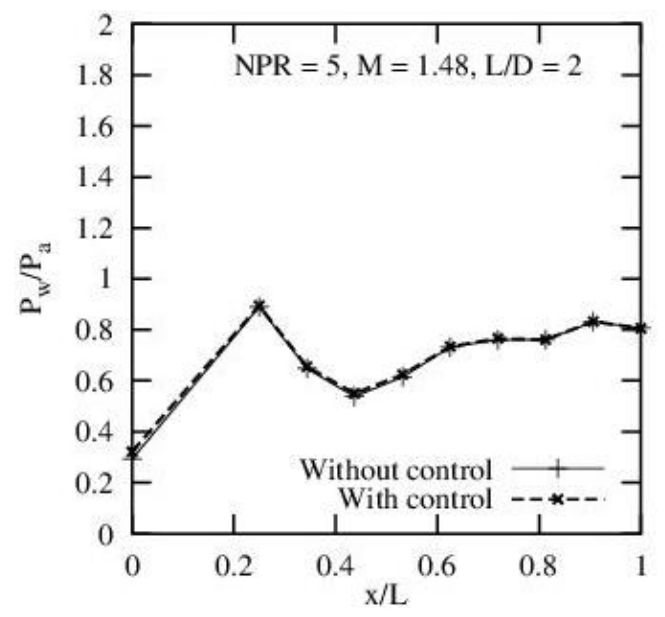

Fig. 7 (c)

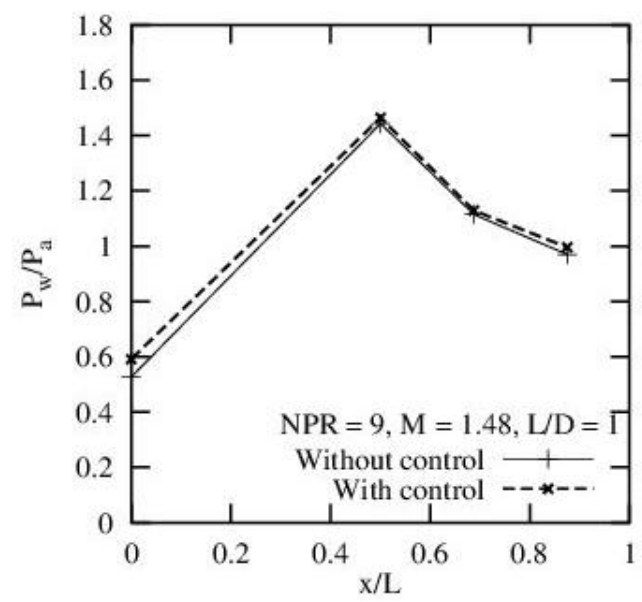

Fig. 8 (a)

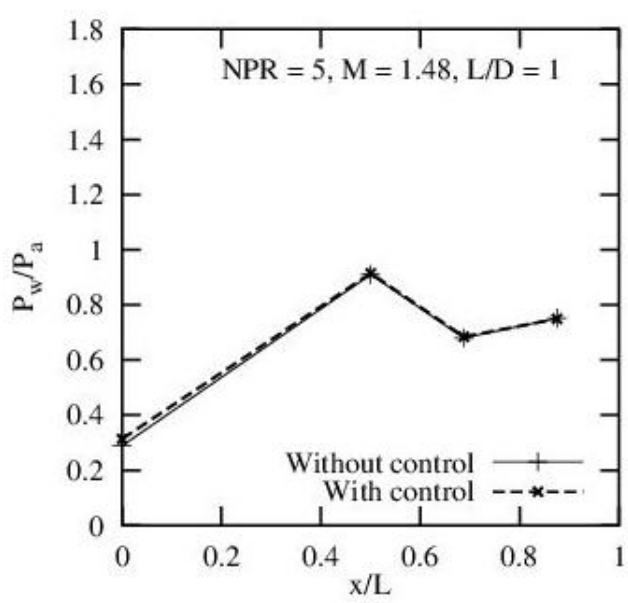

Fig. 8 (c)

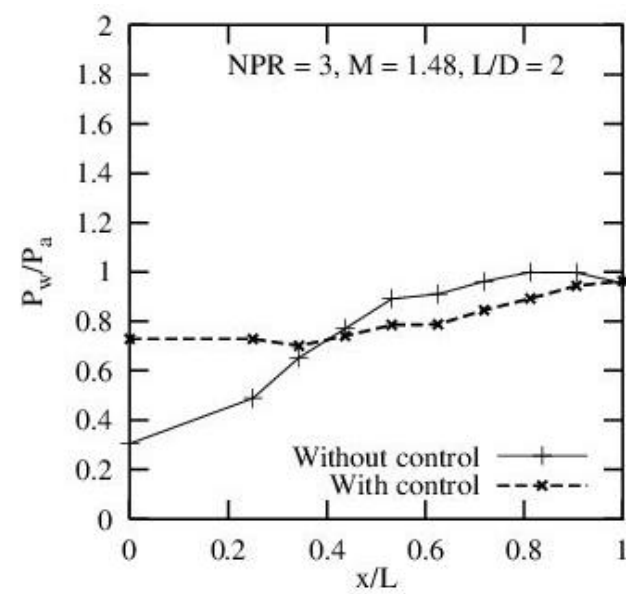

Fig. 7(d)

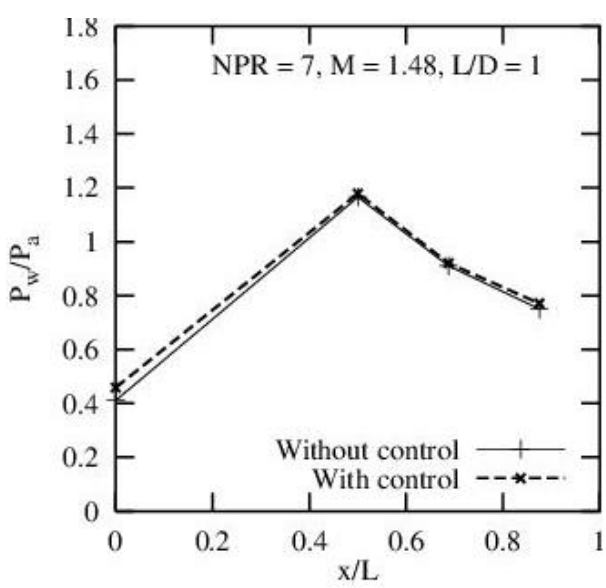

Fig. 8(b)

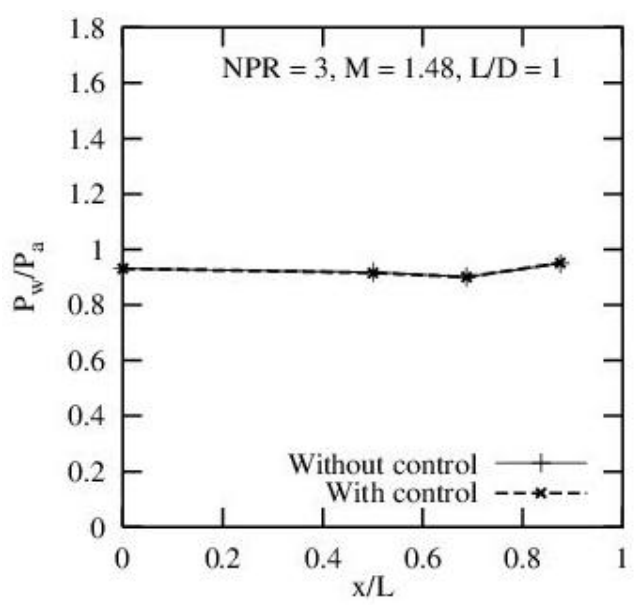

Fig. 8(d)

\section{Conclusions}

Based on the above discussion we draw the following conclusions.

- It is seen that at NPR $=9$ and 7 the entire flow field in the duct is full of waves, the very first shock wave is so powerful that the wall pressure is equal to the atmospheric pressure or even more than that of back pressure, as observed for $\mathrm{L} / \mathrm{D}=10,8,6,5,4$ and 3 , and then through the next shock wave the wall pressure assumes higher value than the atmospheric pressure after the reflection from the wall.The 
control results in reduction of wall pressure by $40 \%$. Later, again the flow under goes through compression and expansion waves.

- $\quad$ For NPR 5 and 3, it is seen that jets are under and over expanded, as it is seen for higher NPRs 9 and 7 that the first shock is very strong. However, for NPR $=3$, it contains only two oblique shocks and after that all pressure value has reached almost to the level of atmospheric pressure.

- When we see the results for NPRs 5 and 3 there is marginal change in the terms of shock strength and number of waves due to the reduction in the duct length at lower L/Ds.

- Results for $\mathrm{L} / \mathrm{D}=2$ trend of the flow field remains the as that of $\mathrm{L} / \mathrm{D}=3$ for NPRs 9,7 and 5, but at NPR $=3$, without control the suction which was created for all the L/Ds NPRs was created is no more visible when active controls are employed and the value of wall pressure increases from as low as 0.3 to 0.75 , this behavior is due to the combined effect of NPR, L/D, and due to the influence of ambient atmospheric pressure.

- For the lowest $\mathrm{L} / \mathrm{D}=1$ the flow is no more attached at NPR $=3$ and when micro jets were employed there is marginal increase in wall pressure for all the NPRs in the range 9 to 7 for $\mathrm{L} / \mathrm{D}=1$.

- In view of the extremely short duct length we should consider the results for $\mathrm{L} / \mathrm{D}=10$ to 2 only for analysis.

\section{References}

[1]. Schmidt, S., et al., Advanced ceramic matrix composite materials for current and future propulsion technology applications. Acta Astronautica, 2004. 55(3): p. 409-420.

[2]. $\quad$ Eilers, S.D., et al., Side-Force Amplification on an Aerodynamically Thrust-Vectored Aerospike Nozzle. Journal of Propulsion and Power, 2012. 28(4): p. 811-819.

[3]. Gad-el-Hak, M., Flow control. Applied Mechanics Reviews, 1989. 42(10): p. 261-293.

[4]. You, D. and P. Moin, Active control of flow separation over an airfoil using synthetic jets. Journal of Fluids and Structures, 2008. 24(8): p. 1349-1357.

[5]. Uzun, A., et al., Flow physics of a pulsed microjet actuator for high-speed flow control. AIAA Journal, 2013. 51(12): p. 2894-2918.

[6]. Kral, L.D., Active flow control technology. ASME FED, Technical Brief, 2000: p. 1-28.

[7]. Khan, S.A. and E. Rathakrishnan, Active control of suddenly expanded flows from overexpanded nozzles. International Journal of Turbo and Jet Engines, 2002. 19(1-2): p. 119-126.

[8]. Roos, F.W., Microblowing for high-angle-of-attack vortex flow control on a fighter aircraft. Journal of Aircraft, 2001. 38(3): p. 454-457.

[9]. Wick, R.S., The effect of boundary layer on sonic flow through an abrupt cross-sectional area change. Journal of the Aeronautical Sciences, 2012.

[10]. Motallebi, F. and J. Norbury, The effect of base bleed on vortex shedding and base pressure in compressible flow. Journal of Fluid Mechanics, 1981. 110: p. 273-292.

[11]. Kruiswyk, R. and J. Dutton, Effects of a base cavity on subsonic near-wake flow. AIAA Journal, 1990. 28(11): p. 1885-1893.

[12]. Khan, S. and E. Rathakrishnan, Control of suddenly expanded flow. Aircraft Engineering and Aerospace Technology, 2006. 78(4): p. 293-309.

[13]. Khan, S.A. and E. Rathakrishnan, Control of Suddenly Expanded Flows from Correctly Expanded Nozzles. International Journal of Turbo and Jet Engines, 2004. 21(4): p. 255-278.

[14]. Ashfaq, S. and S. Khan, Sonic Under Expanded Flow Control with Micro Jets. International Journal of Engineering Research and Applications, 2013. 3: p. 1482-1488.

[15]. Chaudhary, Z.I., et al., Experimental Investigation on the Effectiveness of Active Control Mechanism on Base Pressure at Low Supersonic Mach Numbers, in Innovative Design and Development Practices in Aerospace and Automotive Engineering2017, Springer. p. 197-209.

[16]. Rathakrishnan, E., Effect of splitter plate on bluff body drag. AIAA Journal, 1999. 37(9): p. 1125-1126.

[17]. Wassen, E. and F. Thiele. LES of wake control for a generic fastback vehicle. in 37th AIAA Fluid Dynamics Conference and Exhibit, Miami, USA. 2007.

[18]. Muminovic, R., et al., Robust and model predictive drag control for a generic car model. AIAA paper, 2008. 3859.

[19]. Favier, J., L. Cordier, and A. Kourta, Sur l'optimisation d'actionneurs pour le contrôle d'écoulements. Mécanique \& Industries, 2007. 8(3): p. 259-265.

[20]. Boucinha, V., et al., Characterization of the ionic wind induced by a sine DBD actuator used for laminar-toturbulent transition delay. AIAA paper, 2008. 4210: p. 2008.

[21]. Khan, S.A. and E. Rathakrishnan, Control of suddenly expanded flows with micro-jets. International Journal of Turbo and Jet Engines, 2003. 20(1): p. 63-82.

[22]. Khan, S.A. and E. Rathakrishnan, Active Control of Suddenly Expanded Flows from Underexpanded Nozzles. International Journal of Turbo and Jet Engines, 2004. 21(4): p. 233-254.

[23]. Ashfaq, S., S.A. Khan, and E. Rathakrishnan, Active Control of Flow through the Nozzles at Sonic Mach Number. International Journal of Emerging trends in Engineering and Development, 2013. 2(3): p. 73-82. 
[24]. M.Ahmed Ali Baig, et al., Control of base flows with micro jets. International Journal of Turbo and Jet Engines, 2011. 28(1): p. 59-69.

[25]. M.Ahmed Ali Baig, S.A. Khan, and E. Rathakrishnan, Active Control Of Base Pressure In Suddenly Expanded Flow For Area Ratio 4.84. International Journal of Engineering Science and Technology, 2012. 4(5): p. 1892-1902.

[26]. Khan, S., M. Bashir, and M.A. Ullah, An investigation of base flow control by wall pressure analysis in a suddenly expansion nozzle. 2016.

[27]. Chaudhary, Z., et al., Experimental investigation of the base flow from the nozzles with sudden expansion. International Journal of Applied Engineering Research. 10(92): p. 2015.

[28]. M. Ahmed Ali Baig, S. A. Khan and E. Rathakrishnan "Effect of Mach number In a Suddenly Expanded Flow for Area Ratio 4.84" International Journal of Engineering Research and Applications (IJERA) Vol.2, N0.7, pp 593-599, July 2012.

[29]. M.Ahmed Ali Baig, S.A. Khan, and E. Rathakrishnan, Control of Nozzle Flow in Suddenly Expanded Duct with Micro Jets. International Journal of Engineering Science \& Advanced Technology [IJESAT]. 2: p. 789-795.

[30]. Ashfaq, S., S. Khan, and E. Rathakrishnan, Control of suddenly expanded flow for area ratio 3.61. International Journal of Advanced Scientific and Technical Research, 2013(3): p. 798-807. 